\title{
DEBATES
}

\section{As regras de Direito do Mar e o espaço internacional: estudo sobre as lutas pelo saber jurídico na ONU}

\author{
The rules of the Law of the Sea and international space: a study on \\ the struggle for determining the legal knowledge in the UN
}

\section{Natália Frozel Barros}

\section{Resumo}

Através da análise das negociaçóes diplomáticas sobre o direito do mar na ONU (1973-1982), o artigo estuda a composição das delegaçóes do Brasil, Estados Unidos e França e a atuação de seus membros juristas e de outros profissionais à margem das negociaçóes. Todos encontram-se envoltos numa luta para interpretar as novas regras do direito do mar. Se por um lado, é confirmada a influência do espaço nacional estadunidense sobre a produção desse novo saber jurídico, por outro, identifica-se também a formação de estratégias anti-hegemônicas que se formam no espaço internacional onusiano. Por meio dessas estratégias, os diplomatas dos países periféricos se aliam a produtores menos "nobres" do saber e conseguem introduzir no direito internacional o novo princípio jurídico de "patrimônio comum da humanidade”, contrário aos interesses das maiores potências econômicas da época.

\section{Palavras-chave}

Juristas; Diplomacia; Anti-hegemonia; Espaço Social; Expertise.

\begin{abstract}
By analyzing UN diplomatic negotiations on the law of the sea (1973-1982), this article studies the composition of delegations from Brazil, France and the United States and the performance of their law professionals and other professionals at the margins of negotiations. They all take part in a struggle to interpret the new rules of the law of the sea. On the one hand, this work confirms the United States' influence on the production of this new legal knowledge. On the other hand, it also demonstrates that anti-hegemonic strategies are built in the international field during the negotiation process. Diplomats from peripheral countries ally themselves with less "noble" experts and manage to introduce into international law the new legal principle of "common heritage of mankind", which goes against the interests of the main economic powers of the time.
\end{abstract}

\section{Keywords}

Law Professionals; Diplomacy; Anti-hegemony; Social Field; Expertise. 


\section{Introdução}

Através da análise do processo de negociação diplomática das leis internacionais sobre o direito do mar na ONU, o artigo analisa a composição das delegaçôes do Brasil, Estados Unidos e França e a atuação de seus membros “juristas” para revisitar a análise de Yves Dezalay e Briant Garth (2002). Segundo esses autores, a hegemonia americana é produto da influência do campo nacional estadunidense sobre o processo de unificação do campo mundial dos saberes jurídicos. O presente artigo confirma a preponderância do centro do sistema mundo no trabalho de produção doutrinária, ou de legitimação jurídica das leis internacionais, mas identifica também a formação de estratégias anti-hegemônicas que se formam durante o processo de negociação diplomática estudado. Por meio dessas estratégias, os diplomatas dos países periféricos conseguem introduzir no direito internacional do mar o novo princípio jurídico de "patrimônio comum da humanidade".

Como seria de se esperar, professores de direito de diferentes nacionalidades e universidades integram as delegaçóes de todo o mundo quando essas se encontram nas Nações Unidas para redigir as regras jurídicas de um novo tratado internacional. A aparente banalidade e de suas presenças e pluralidade nacional dá lugar a uma curiosa homogeneidade quando nos interessamos sobre suas origens, formações profissionais e os laços sociais mantidos entre eles mesmos e outros profissionais internacionais: eles estudaram, em sua grande maioria, nas mesmas faculdades de direito na Europa ou nos Estados-Unidos. Seria essa homogeneidade um sinal daquilo que Yves Dezalay e Briant Garth (2002) identificam como a unificação do campo mundial, provocada pela exportação da guerra de palácios dos centros ocidentais do sistema mundo para outros países através da exportação de um saber de Estado?

A fim de responder a essa questão, esse artigo toma como estudo de caso a III Conferência das Nações Unidas sobre o Direito do Mar (1973-1982) e a produção de leis ou regras de direito sobre os fundos marítimos que compóem hoje a Convenção das Nações Unidas sobre o Direito do Mar (CNUDM). Aborda-se esse estudo de caso sob o prisma da tradição da sociologia das elites (BOURDIEU, 1989; PERISSINOTTO e CODATO, 2008) e dos trabalhos sobre a internacionalizaçáo de elites (jurídicas) nacionais (DEZALAY e GARTH, 2002; ALMEIDA, 2004; ENGELMANN, 2012). Se o intuito é dialogar com esses últimos trabalhos através da análise de um processo de negociação de leis jurídicas internacionais, esse diálogo faz parte de um trabalho mais amplo que visa questionar com as ferramentas da sociologia política o debate já clássico em relaçóes internacionais sobre os circuitos de 
construção das normas internacionais (FINNEMORE e SIKKINK, 1998; KECK e SIKKINK, 1998) intrinsicamente ligadas aos saberes ou ciências de Estado, como exploraremos aqui.

Através do estudo de caso da CNUDM (1982), se mostrará, primeiramente, como os atores políticos das negociações diplomáticas recorrem obrigatoriamente aos profissionais universitários com a finalidade de obter a autoridade jurídica necessária para negociar nas melhores condiçôes. Porém, se analisará em seguida como, às margens do mesmo processo de negociação, os atores políticos dominados internacionalmente - diplomatas da África, Ásia e América Latina - encontram uma aliança frutífera com os atores jurídicos dominados no espaço nacional do centro, os juristas-ativistas norte-americanos (e ocidentais). Desse encontro, estratégias antihegemônicas se forjam e colocam em causa a tradicional centralidade dos guardióes da doutrina do direito internacional, os professores de direito público internacional das grandes universidades europeias e estadunidenses. Antes, no entanto, é indispensável conhecer o contexto das negociações sobre os fundos marinhos e a metodologia empregada para analisá-lo.

\section{Uma polêmica jurídica no fundo do mar}

Ao longo dos nove anos de negociaçóes diplomáticas, os poucos centros e universidades especializados em direito internacional estavam concentrados nos centros clássicos do sistema mundo, como as universidades mais reputadas dos Estados Unidos e da Europa. Seria assim de se esperar, como resultado dessas negociaçôes, que as novas regras de direito do mar fossem próximas às interpretaçôes doutrinárias, para alguns científicas, dos juristas desses centros que concentram uma certa autoridade intelectual mundialmente reconhecida. No entanto, o resultado é contrário às expectativas. Várias das novas regras trazem um caráter insólito ao direito internacional: cria-se, por exemplo, uma "zona econômica exclusiva”, inédita, de 200 milhas marítimas sendo que antes os Estados se projetavam quase exclusivamente em termos de soberania total e sobre uma faixa de três milhas. Uma outra invenção, que estará no centro da nossa análise, é o princípio de patrimônio comum da humanidade aplicado aos recursos minerais do fundo do mar em toda a área internacional dos oceanos.

Porque o fundo do mar é declarado patrimônio comum da humanidade, as regras de 1982 da convenção estipulam que toda empresa que explora minérios nesse 
ambiente tem que, obrigatoriamente, transferir parte de sua tecnologia aos países em desenvolvimento através da Autoridade Internacional dos Fundos Marinhos. Elas preveem também que as empresas paguem à Autoridade taxas e porcentagens dos benefícios econômicos provindos destas atividades. Os recursos serão mais tarde distribuídos de forma equitativa entre os países em desenvolvimento. Tais regras favorecem aqueles países deficitários em tecnologia e que se encontram, por essa razão, incapacitados de explorar e se beneficiar dos fundos marinhos. Em compensação, elas impóem obrigaçóes pesadas aos governos e empresas dos países industrializados. Uma clivagem econômica Norte-Sul se materializa assim nessas regras e nas controvérsias que as acompanham.

A clivagem econômica deve ser compreendida através da forte atuação do Grupo dos 77. Esse grupo, de cerca de 120 países em desenvolvimento ${ }^{1}$, se manteve unido apesar das fortes dissençóes internas e promoveu a leitura econômica e equitativa do princípio por meio de estratégias de condicionalidade nas negociaçóes (ex. o grupo fez concessóes sobre a pauta militar e estratégico de navegação, cara às grandes potências, para obter ganhos na pauta econômica sobre o fundo do mar). $\mathrm{Na}$ medida em que esse grupo ganha certo momentum nas negociações, e que as novas regras de transferência de tecnologia e de benefícios econômicos começam a se cristalizar, as controvérsias em torno do patrimônio comum da humanidade emergem. Juristas, políticos e diplomatas se dividem entre os que condenam essas regras, como sendo "por demais ideológicas" (RATINER, 1982, p. 1015), e aqueles que as defendem como um "sucesso do pragmatismo" (DE SOTO, 1983, p. 67). Para os primeiros, mais próximos dos países ocidentais, o patrimônio comum da humanidade não deriva do direito sendo somente um tipo de slogan político. Para os segundos, mais próximos dos países em desenvolvimento, ele é justamente o novo direito ou o direito renovado. Uma controvérsia sobre a juridicidade do princípio toma forma ou, em outras palavras, instala-se uma disputa para nomear o direito. Ora, tradicionalmente, essa função de nomear o direito recai sob a competência dos guardióes tradicionais do direito público internacional, os grandes professores de direito que glosam sobre a doutrina jurídica. Não satisfeitos com uma explicação que se contentaria em afirmar que a luta política coloca em segundo plano toda autoridade jurídica, e instigados por essa aparente contradição entre slogans políticos que se tornam regras de direito, o presente artigo questiona a força social desses

\footnotetext{
${ }^{1}$ O grupo conta por volta de 97 membros no começo das negociaçôes em 1973 e termina com 122 em 1982.
} 
juristas consagrados exercida sobre o processo diplomático de negociação em questão e, mais especificamente, sobre o patrimônio comum da humanidade.

\section{Metodologia}

No centro da análise encontram-se os atores juristas e aqueles que entram em concorrência com eles ao longo das negociaçôes. A fim de identificá-los, foi contruída, primeiramente, uma base de dados à partir dos documentos oficiais de credenciamento para a III Conferência sobre o Direito do Mar depositados nos Arquivos da Organização das Nações Unidas. A base é composta por 536 indivíduos membros das delegações do Brasil, Estados-Unidos e França entre 1973 e 1982 e contem informaçôes sobre a instituição e o cargo ocupado por cada indivíduo no nível nacional, assim como título honorífico (embaixador, comandante etc.) e a posição ocupada na hierarquia interna da delegação diplomática no âmbito das negociações onusianas (chefe da delegação, conselheiro, especialista). Os primeiros dados permitem identificar a filiação profissional do indivíduo, enquanto os segundos possibilitam identificar se ele assumiu papel de protagonista (ex. negociador), de conselheiro nas sombras ou simplesmente de observador. Em seguida, um trabalho nos seguintes arquivos foi realizado para identificar os atores que atuam às margens das delegações: autos das reuniôes da International Law Association, os fundos pessoais de Elisabeth Mann Borgese depositados nos arquivos Dalhousie University e, de forma mais marginal, os relatórios e estudos de outros think-tanks e professores universitários. A análise se apoia na reconstrução das trajetórias e nas práticas desses atores, prestando atenção a como eles passam do espaço nacional ao espaço internacional onusiano ajustando ou não seus discursos, identidades e ações. Aliando assim uma análise estrutural ao tempo longo das negociações, identificou-se como grupos de atores com propriedades sociais próximas criam alianças e oposiçóes que tornam possível que uma interpretação do direito vingue em detrimento de outra.

\footnotetext{
${ }^{2} \mathrm{Na}$ ordem citada no texto: Seção dos arquivos e registros das Nações Unidas, cota S-0571-(00010019), Law of the Sea Conference (Credentials), consultados entre 25 de novembro e 17 de dezembro de 2015 a Nova Iorque (ILA); Dalhousie University Archives, Fundos Elisabeth Mann Borgese, Halifax, Nova Scotia, Canada, consultados entre 2017 e 2018.
} 


\section{Professores e juristas no centro do processo de negociação...}

No centro das negociações sobre o direito do mar encontram-se as delegações diplomáticas, verdadeiros ecossistemas profissionais. Parlamentares e diplomatas, executivos de empresas petrolíferas e militares das marinhas nacionais, representantes de sindicatos da pesca e magistrados, funcionários dos ministérios da Defesa e do Comércio. Os perfis estão distribuídos desigualmente entre 150 delegações e as 16 sessóes de trabalho da conferência, mas uma constante salta aos olhos: a presença dos professores das faculdades de Direito.

De três países estudados mais detalhadamente (Brasil, Estados Unidos e França), a delegação estadunidense é a única a contar com advogados de gabinetes privados especializados em direito comercial e empresarial, de acordo com tendências estudadas em outros trabalhos (DEZALAY, 1992). Em compensação, todas as delegações contam com professores de direito e funcionários governamentais juristas. Estes últimos vêm de ministérios, departamentos e secretarias que variam de acordo com o organograma governamental de cada país, mas também de acordo com a agenda internacional dos oceanos é captada, problematizada e tratada em cada um desses países. Assim, e sob o risco de cair no prosaico, constata-se que havia mais observadores e negociadores vindos dos corpos militares dos Estados-Unidos (25 representantes) que da França (18 representantes) (Cf. supra metodologia). Já entre os funcionários dos ministérios exteriores, franceses e estadunidenses contam com conselheiros legais vindos da Direction des affaires juridiques ou do Office of the legal adviser de seus ministérios, enquanto os brasileiros são representados por diplomatas tidos como generalistas, um reflexo do espírito de "não especialização" do Itamaraty. O espaço de negociação multilateral é assim composto por atores profundamente diferentes e com sensibilidades diferentes ao direito e ao direito internacional. Essas variações desaparecem, porém, em relação a um setor específico: todas as delegações mobilizam seus guardióes tradicionais do Direito Internacional. 


\section{a) As trajetórias dos professores de Direito: entre estratégia profissional e cooptação burocrática}

Assim, o professor titular da cátedra de Direito Internacional Público da Faculdade do Largo do São Francisco, da Universidade de São Paulo (USP), Vicente Marotta Rangel, acompanha as negociações, do começo ao fim, como membro da delegação brasileira. René-Jean Dupuy, Doutor pela Sorbonne, professor da Faculdade de Direito de Nice e titular da cátedra de Direito Internacional do Collège de France; Claude Albert Colliard, da Faculdade de Direito de Paris (Sorbonne); Daniel Bardonnet e Jean-Pierre Queneudec das faculdades de Paris II et Montpellier, participam de forma mais ou menos intermitente pela delegação francesa. E, por fim, Louis B. Sohn da faculdade de direito de Harvard, William Burke da Universidade de Washington et Bernard H. Oxman, funcionário do serviço jurídico da marinha e professor da Universidade de Miami, integram a delegação estadunidense. Suas trajetórias apresentam pontos semelhantes e comuns entre si, interessantes do ponto de vista sociológico.

No que tange os pontos semelhantes, Rangel, Colliard, Dupuy e Sohn ocupam posições a capital diferente internacionalmente (USP e Harvard), mas homólogas nacionalmente: eles ocupam a cátedra de Direito Internacional nas faculdades mais prestigiosas de seus respectivos países. Quanto aos pontos em comum, por sua vez, todos eles passaram, em algum momento da formação acadêmica, pelas universidades francesas (Sorbonne) e americanas (Harvard, Georgetown), instituiçóes dentre as mais reputadas internacionalmente. Isso fica particularmente claro quando se analisa a trajetória do professor brasileiro. Marotta Rangel obteve sua graduação na Faculdade São Francisco em 1946 e, em seguida, parte para Paris, onde obtém em 1950 o título de Doutor em Direito Público Internacional pela Faculdade de Direito da Sorbonne. Ao retornar ao Brasil passa a lecionar em São Paulo a partir de 1957. Sua trajetória, representativa de muitas outras, corrobora outros estudos sobre os profissionais do direito no Brasil e no mundo (DEZALAY e GARTH, 2002; ENGELMANN, 2012), e mostram como esses guardióes da doutrina jurídica possuem em comum os diplomas vindos dos polos universitários mais centrais mundialmente: a França e os Estados Unidos, Sorbonne e Harvard. Esse quadro mínimo de homogeneidade entre as delegações da conferência diplomática pode ser duplamente interpretado e a trajetória do professor estadunidense Louis B. Sohn servirá de base para essa interpretação. De forma mais 
breve e ilustrativa, será feito o paralelo com os outros delegados, sempre que pertinente.

Se participar da grande quermesse onusiana faz parte das estratégias profissionais típicas das carreiras dos professores de direito internacional público, pode-se afirmar que Sohn possui uma carreira acelerada e "exemplar" graças a uma socialização precoce nos meios político-jurídicos que participam na construção das organizaçôes internacionais do pós II Guerra Mundial. Essa participação só é possível graças a seu tutor em Harvard, Manley O. Hudson, professor e juiz da Corte Permanente de Justiça Internacional. Ao convite deste último, Sohn se aproxima das elites americanas que promovem a criação da ONU, participa ativamente da Segunda Conferência de Dumbarton Oaks - responsável pela concepção da nova corte de justiça -, e, aos 31 anos de idade, assume o papel de relator das reunióes sobre o estatuto da nova Corte Internacional de Justiça no âmbito da Conferência de São Francisco em 1945. Graças a sua rede harvardiana, Sohn multiplica seus contatos em meio às elites norte-americanas e internacionais e acumula uma experiência prática digna de um grande professor de Direito Internacional. Essa experiência lhe abrirá portas para integrar a representação estadunidense nas negociações sobre o Direito do Mar. Dupuy ocupa a mesma dupla posição - nacional e internacionalmente - sendo o primeiro membro francês da Comissão Europeia de Direitos Humanos (19741980), entre outros exemplos. Cerca de dez anos mais novo que Sohn e Dupuy, Marotta Rangel inicia também essa carreira dupla - acumulando posições nacionais e internacionais - a partir de sua participação na III Conferência. Essa experiência lhe abrirá as portas da Corte Permanente de Arbitragem de Haia (1979-2003) e do novo Tribunal de Direito do Mar, onde ele será juiz (1994-2015). Essas experiências no espaço político jurídico internacional aceleram o acúmulo de distinções, posições sociais e conhecimento prático sobre o direito internacional àqueles mesmos que consagram esse direito por meio de uma produção doutrinária nas grandes universidades.

Por outro lado, toda delegação nacional busca, de acordo com os meios a sua disposição, os capitais simbólico e social que somente esses profissionais podem trazer à negociação: eles se encontram assim tomados por lógicas de cooptação burocrática. Não se trata aqui de afirmar simplesmente que os governos nacionais buscam os "melhores" juristas das "melhores" faculdades de direito, mas de entender o que significa socialmente esse adjetivo "melhor". Sohn, por exemplo, será responsável, no âmbito da Conferência, de negociar, entre outros temas, os mecanismos de resolução de litígios, tarefa para a qual ele possui uma experiência ímpar após a criação da Corte 
Internacional de Justiça. Marotta Rangel, por sua vez, é convidado pelo Itamaraty também porque dedicou sua tese para a obtenção da cátedra na USP ao tema sobre o mar territorial. A especialização é, portanto, um fator que contribui, mas não será o único. Um outro "cálculo" de ordem menos racional e mais social é aquele do capital social que esses atores compartilham com os juristas de outros espaços sociais nacionais, em especial o espaço governamental.

Assim que o fundo do mar se torna um problema público no âmbito da ONU, um grupo de trabalho interdepartamental é criado nos Estados Unidos para definir a posiçáo nacional sobre o tema. Em 1969, Sohn era o primeiro conselheiro em direito público internacional no Departamento de Estado e já colecionava quase uma década de cargos de conselheiro em diversos setores governamentais estadunidenses. Ele integra então a equipe de consultas interdepartamentais sobre os oceanos, antes mesmo da formalização de uma delegação. Ora, sua posição tem de ser tomada como resultado da sua rede social iniciada anos atrás pelo juiz internacional e seu mentor - Hudson, e de suas experiências em outras negociações internacionais. Porém, um olhar mais atento nos permite constatar que Sohn ganha acesso a essa posição no seio do poder estadunidense somente após obter seu cargo oficial de Professor da Harvard. Essa instituição encontra-se assim no centro da estratégia de reprodução de professores e juristas próximos do centro do poder e permite compreender melhor a força social dos professores universitários, principalmente ocidentais, no momento da negociação.

\section{b) Da centralidade dos professores ocidentais no espaço onusiano de negociação diplomática}

Se as estratégias profissionais dos professores de direito e as lógicas de cooptação burocrática dos governos nacionais levam esses atores ao espaço internacional de negociação diplomática, elas não asseguram a mesma proeminência nesse espaço. O peso de Harvard no recrutamento nacional de Sohn é ainda maior quando consideramos que esse professor é o laço mais antigo de uma corrente social jurídica e harvardiana que se esboça no espaço circunscrito das negociaçóes sobre a CNUDM.

Para além da figura do guardião da doutrina do direito ou dos professores universitários, Harvard produz também juristas-negociadores para vários países do globo como explica o advogado Elliot Richardson, chefe da delegação estadunidense: 
Eu fui um dos cerca de 38 de seus antigos estudantes espalhados por quase o mesmo número de delegaçóes [na III Conferência do Direito do Mar]. Nós o procurávamos não somente para obter orientação e conselhos, mas para rejuvenescer nosso entusiasmo toda vez que o trabalho da Conferência nos parecia, mais do que era o costume, frustrante (RICHARDSON, 1984, p. 149).

Essa rede ampla de estudantes e profissionais do Direito reforça o reconhecimento do qual desfruta Sohn já nesse meio diplomático. É o que descreve esse outro antigo aluno de Sohn que também participou das negociações:

Eu atuava como o conselheiro jurídico a um grupo de 'países insulares e geograficamente desfavorecidos' durante a década de negociaçóes sobre o direito do mar. Sohn, um delegado dos Estados Unidos, organizou o que acabou se tornando naquela conferência um contínuo seminário sobre a resolução pacífica de conflitos. Muitos dos representantes que, durante anos, participaram religiosamente do seminário eram seus ex-alunos como eu. Daquele seminário saiu o Anexo 7 da Convenção sobre o Direito do Mar, que estabelece o modelo de resolução obrigatória de conflitos (FRANCK, 2007, p. 824).

Dar aulas, a função primeira de um professor, seja em Harvard ou dentro da ONU reflete, antes de mais nada, um domínio dos códigos sociais de diferentes espaços e uma capacidade de reproduzir sua primeira identidade, aquela de professor, mesmo em situaçóes de multi-posicionalidade contraditória: ele assume o papel de professor dos membros das delegaçôes "adversárias". Esse episódio é tão anedótico quanto representativo de outras situaçóes ${ }^{3}$. Acima de tudo, ele reflete toda a estrutura social transformada em força simbólica ou esse gravitas jurídico durante as negociações. Esses professores, e principalmente aqueles mais centrais vindos dos países ocidentais, trazem essa força simbólica às relaçôes micro-sociais de uma negociaçâo internacional. É pouco espantoso então encontrar em todas as delegaçôes essa mesma figura do "professor de direito internacional" e constatar a imposição

\footnotetext{
3 Outras redes de alunos das universidades mais centrais se formaram. Por exemplo, o delegado australiano Elihu Lauterpacht, também jurista, mas formado pela Universidade de Cambridge, organizava reunióes entre os delegados que haviam estudado na faculdade de direito inglesa, durante as sessóes da conferência (TELTSCHNYT, 1977).
} 
simbólica dos professores de Harvard, Cambridge e Sorbonne em meio às negociaçóes.

Além disso, os efeitos dessas lógicas profissionais e governamentais sobre o processo de negociação tendem a favorecer que os professores ocupem posições relativamente centrais no jogo da negociação, principalmente se os comparamos com outros juristas integrantes das delegaçóes. É ilustrativo, por exemplo, a trajetória e atuação de Sohn em comparação às do advogado e ativista Aaron Danzig, também membro da delegação americana. Este último é acreditado na lista da delegação como advogado de um gabinete de direito comercial e empresarial baseado em Nova Iorque, o que aliás the proporciona uma rede social não negligenciável em meio às elites norte-americanas. Ele é também o autor do relatório da associação World Peace Through World Law (julho 1967) que propóe que os fundos marinhos sejam reconhecidos como patrimônio comum da humanidade antes mesmo que o tema chegue à ONU (novembro 1967). Esse defensor notório do patrimônio comum parece ter menos influência direta no jogo diplomático do que o professor Sohn.

O professor de Harvard participa das negociaçóes desde 1970 até o fim desse processo e ocupa um papel preponderante como negociador direto em pelo menos uma das comissões da conferência. Danzig, por sua vez, participa principalmente nos primeiros anos (1975-1978) e de forma intermitente, ocupando papeis mais marginais como observador enquanto se dedica a outras atividades fora desse processo de decisão internacional. Sobre um outro episódio das negociações, John T. Smith, assistente do chefe da delegação estadunidense, Elliot L. Richardson, descreve a centralidade do professor. Quando Richardson chega à direção da delegação, no início da administração Carter, encontra as negociações bloqueadas por fortes polarizaçôes. No intuito de melhor participar do processo Richardson mergulhou nos temas do Direito do Mar, "relembrou Smith, 'passando longos períodos com os [professores de direito internacional] Bernie Oxman e Louis Sohn... horas e horas de briefings e discussões" (VISWANATH, 2009, p. 37). O fato do chefe da delegação dos Estados Unidos procurar os conselhos daqueles que acompanham as negociaçóes desde o início é compreensível e até evidente que assim o fosse.

Interessante, porém, é destacar o fato de Richardson aconselhar-se com os "professores de direito" e, mais precisamente, com o seu professor de direito de Harvard, Louis B. Sohn. Mais uma vez se repete a lógica fundada nos laços sociais estabelecidos no espaço harvardiano e mantidos em volta da figura do "professor". Isso não equivale a dizer que Sohn ou Richardson não tivessem nenhuma simpatia 
pela causa de Danzig mas que existe uma lógica profissional e social presente na composição e dinâmica internas da delegação estadunidense. Danzig, advogado comercial e ativista em favor da "paz internacional pelo direito", ocupará um papel mais marginal que Sohn na dinâmica de tomada de decisão interna da delegação.

Ora, se constatamos assim uma certa marginalização dos advogados ativistas em comparação aos guardiōes da doutrina do direito internacional, os primeiros não são, no entanto, excluídos do processo de negociações. Eles participam indiretamente, entrando pelas portas do fundo da "expertise independente".

\section{... juristas e ativistas nas margens do processo de negociação}

À margem desse núcleo dos profissionais acreditados oficialmente como membros das delegaçóes nacionais, outros tentam dizer o que é, ou ainda melhor, o que deve ser o princípio de patrimônio comum da humanidade. Várias associações gravitam em torno das negociaçôes onusianas dobre o direito do mar. Dentre aquelas mais engajadas no trabalho de produção de expertise, encontramos dois perfis diferentes: a International Law Association, associação à filiação profissional, e o Center for the Sudy of Democratic Institutions, um think-tank estadunidense promotor de ideias liberais.

A Associação de Direito Internacional fundada no século XIX é herdeira dos primeiros juristas ocidentais que promoveram a criação e estabilização de um direito interestatal internacional (KOSKENNIEMI, 2002; SACRISTE e VAUCHEZ, 2005). Com tal objetivo, ela se erigiu como uma instituição à identidade profissional e manteve a filiação de membros exclusivamente juristas, no sentido primeiro da palavra: essencialmente professores de direito e somente alguns advogados. Ademais, as filiais ocidentais dominam tradicionalmente os trabalhos em curso ${ }^{4}$. O Center for the Study of Democratic Insitutions, mesmo se fundado por um jurista de Yale em 1959, é um think-tank próximo da "grande aliança das elites profissionais americanas" que sobrevive dos financiamentos de fundações como a Fundação Ford (DEZALAY e GARTH, 2002, p. 119). Ele agrupa diferentes intelectuais em torno, inicialmente, da causa pelos direitos civis e, em seguida, se abre aos temas internacionais. Ele conta com a participação de figuras centrais do direito e da política, domésticos e internacionais, como o Attorney General Robert F. Kennedy, o

\footnotetext{
${ }^{4}$ Por exemplo, em 1976, havia 26 membros da Europa, 7 da América do Norte, 3 da Austrália, 9 da Ásia, 4 da América latina e nenhum da África (ILA, 1976).
} 
juiz da Corte Suprema Americana William O. Douglas, Marthin Luther King Jr. e Henry Kissinger. Nessas duas instituições - distintas mas não isoladas uma da outra-, o direito do mar se torna um objeto de debate durante a década de 1970.

\section{a) O ativismo juridico "erudito"}

No seio da Associação profissional e que se reclama a vocação de tratar "academicamente" (scholarly) (ILA, 1978, p. 74-75, tradução da autora) dos novos temas de Direito Internacional, os membros do comitê se concentram mais longamente sobre os elementos clássicos do Direito do Mar (ex. delimitação territorial) e deixam de discutir a questão do fundo do mar à medida em que as negociaçóes avançam na ONU. Nessa mesma progressão as mençóes cada vez mais breves sobre o patrimônio comum da humanidade tomam um ar cada vez mais denunciatório. Em 1972, os profissionais têm debates acesos sobre a legalidade do princípio; em 1974 e 1976, eles fazem menos referência ao mesmo; e, em 1978, o relator da Associação, o australiano e professor nos Estados-Unidos L.F.E. Goldie descreve-o como "ideológico" (ILA, 1978, p. 322). Se alguns advogados provindos dos países em desenvolvimento participam e defendem o princípio de patrimônio comum, eles não ocupam posições centrais no trabalho da Associação. Nesse espaço dominado pelos guardióes da doutrina do direito internacional, vindos dos países mais centrais, não encontramos o mesmo trabalho entusiasta de interpretação jurídica do patrimônio comum que encontramos nos think-tanks ativistas que estudaremos detalhadamente em seguida. Em outras palavras, as portas principais, guardadas pelos professores de direito das universidades estadunidenses e europeias, parecem fechadas a esse novo conceito Porém, se o que se passa dentro dessa associação coloca em questão a "vocação" jurídica dessa nova ideia, a proliferação de discussões e relatórios sobre o patrimônio comum da humanidade desenvolvidos dentro dos think-tanks liberais estadunidenses contribui para a sobrevivência do princípio ao longo dos nove anos de diálogo diplomático. 


\section{b) O ativismo juridico "profano"}

Nesse sentido, é ilustrativa a atuação da funcionária do Center for the Study of Democratic Institutions, Elisabeth Mann Borgese. Essa mulher cosmopolita, filha do escritor Thomas Mann, organiza uma série de conferências intituladas Pacem in Maribus (paz sobre o mar). Borgese não é jurista e sim uma cientista política interessada na questão da constituição mundial ou de um governo internacional para assegurar a paz mundial (MAZOWER, 2013). No âmbito dessas reflexóes, ela escolhe a questáo do regime do fundo do mar como um novo meio de propor ideias inovadoras em favor de um controle internacional dos fundos marinhos e em nome da paz mundial. Como interlocutora do Center, ela se torna próxima ao diplomata e jurista maltês Arvid Pardo, fundador da ideia de patrimônio comum da humanidade na ONU e negociador na conferência. Ela mantém contato também com o senador Claiborne Pell, um democrata entusiasta do princípio de patrimônio comum, mas, por conta disso, isolado no senado americano. No encontro desses atores, três redes se unem aqui: a política, próxima das elites governamentais americanas graças ao cargo que Borgese ocupa no Center e à contribuição do senador Pell; a rede cosmopolita e de expertise de Borgese; e, por último, a diplomática, do embaixador Pardo, que atua como um ator central nas negociaçóes do direito do mar. Borgese e Pardo, mais especificamente, convencem os diplomatas da conferência do direito do mar, e em especial aqueles dos países em desenvolvimento, a participarem das reunióes Pacem in Maribus em Nova Iorque (1970) ao lado de ativistas e profissionais pelo direito internacional. A consolidação dessas três vertentes resulta em uma nova rede de expertise fora do espaço das negociaçóes e é possível graças à confluência de lutas acontecendo em dois espaços interconectados.

Por um lado, no âmbito nacional nos Estados Unidos, o senador democrata Pell aproveita o espaço dessas conferências para defender um engajamento solidário do país internacionalmente enquanto funcionários mais próximos do gabinete presidencial tratam dos fundos marinhos como uma questão puramente securitária e a ser resolvida primordialmente com a URSS. Por outro lado, alguns países em desenvolvimento e não alinhados começam a contestar essa liderança americana e soviética na ONU. Aqui repousam os germes de uma divisão Norte-Sul no âmbito das negociaçôes que serão importados para o espaço nacional americano. A primeira reunião de Pacem in Maribus é o resultado de uma articulação de bastidores entre Pell, Borgese e os embaixadores não alinhados da Índia e da Iugoslávia. Face à táctica 
americano-soviética de reduzir os fundos do mar a uma questão securitária, ignorando os anseios econômicos de outros países, esses outros atores promovem a questão da exploração econômica dos fundos marinhos por meio das reuniões de Borgese (BAKER, 2009). No interstício dessas duas lutas, nacional e internacional, se forja uma aliança tácita entre políticos, experts, diplomatas e ativistas em 1970.

\section{c) Como os "profanos" interpretam o patrimônio comum da humanidade ou as práticas pelas quais os espaços nacional e internacional se conectam e se sustentam}

Nas próximas ediçôes de Pacem in Maribus esse padrão heteróclito continua. Em 1970, vinte diplomatas e funcionários governamentais vindos de países em desenvolvimento debatem com especialistas de todo o mundo (num total de 241 convidados). Aqui uma diferença em relação à Associação de Direito Internacional é visível: diferentemente de membros juristas-advogados e juristas-professores ocidentais, o Center vai vincular um espectro mais amplo de profissionais, e em muitos casos, vindos dos países mais dominados internacionalmente. Dessa forma, os membros do Center e os vários atores que circulam pelas reuniôes do Pacem in Maribus são indivíduos que passaram menos pelos "lugares institucionais nos quais se constroem a legitimidade e a hierarquia das produções doutrinárias" (DEZALAY, 1993, p. 233) como, por exemplo, as faculdades de direito mais centrais, os concursos e agregaçóes para a obtenção de cátedras, as revistas e colóquios renomados. A distância que esses atores mantêm das instituições legítimas da produção doutrinária não os impede, no entanto, de promover uma leitura específica do que é e do que deve ser a ordem jurídica internacional sobre os oceanos. Ao contrário, esse encontro de ocasião servirá como um espaço a dupla função: um espaço de captação de recursos jurídicos pelos atores dominados nas negociações internacionais (1) e um espaço alternativo de formalização e interpretação "doutrinária" do patrimônio comum da humanidade (2). A forma como as reuniōes Pacem in Maribus se institucionalizam após a criação de um novo centro especializado nos assuntos oceânicos, o International Ocean Institute (IOI), evidencia essas duas funçóes.

Uma vez formada a rede de especialistas e diplomatas através do Center for the Study of Democratic Insitutions e, face às dificuldades financeiras desse último, 
Borgese funda o International Ocean Institute (IOI) em 19725. As duas organizações continuarão a trabalhar em conjunto por alguns anos ainda. Os diplomatas dos países em desenvolvimento continuam igualmente a trabalhar com Borgese e procuram no IOI interlocutores e recursos mais centrais internacionalmente. O Instituto produz todo um trabalho de pesquisa e publicação sobre os temas da conferência. Trata-se assim de um canal para obter recursos para a negociação na ONU, como explica Borgese numa correspondência pessoal. Além das publicaçóes, ela prevê também criar conferências regionais no intuito de que estas sejam "úteis às naçôes menores, especialmente àquelas da África e da Ásia que não dispóem do pessoal e da documentação que eles possam vir a precisar no desenvolvimento de suas políticas públicas" (1) (BAKER, 2009, p. 28). Através dessa estratégia institucional, é possível compreender como o engajamento dos diplomatas e juristas dos países em desenvolvimento no espaço originalmente americano de defesa do direito internacional justifica a fundação da IOI e lhe dá uma raison d'être. De fato, eles trazem para esse espaço uma nova leitura do "patrimônio comum da humanidade" conectado em especial ao movimento dos não alinhados. Onde Borgese via originariamente uma ocasião para criar um governo internacional dos oceanos para assegurar a paz mundial, os diplomatas dos países do Sul trazem uma causa mais econômica: o novo princípio é necessário para tornar mais equitativas as relações entre Estados ricos e pobres. Esses diplomatas se encontram assim num espaço de expertise menos consagrado que aquele dos professores de direito e, apesar disso, criase um espaço social não negligenciável em termos de capital social. Jorge Castañeda, Eggerton Richardson, ministros de assuntos exteriores do México e da Jamaica, e Shirley Amerasinghe e Hambro, embaixadores do Sri Lanka e da Noruega junto à ONU, compóem ao lado de personalidades americanas como Paul G. Hoffman da Ford Foundation, os conselhos de administração e de planificação do IOI. Observamos aqui uma recomposição social do think-tank originalmente povoado por especialistas vindos dos círculos norte-americanos.

Além disso, o IOI produz uma série de livros e relatórios formalizando e interpretando essa nova noção de "patrimônio comum da humanidade", realizando assim um trabalho similar àquele de produção doutrinária. A produção desse material

\footnotetext{
5 Paul G. Hoffmann da Ford Foundation, e também por intermédio da Fund for the Republic, um fundo americano alimentado também pela Fundação Ford e a Fundação Ford, ela mesma, constam como alguns dos primeiros doadores ao IOI. Elisabeth Mann Borgese fonds, MS-2-744, Box 24, Folder 35 et Box 48, Folder 12, Dalhousie University Archives, Halifax, Nova Scotia, Canada.
} 
ocorre enquanto os professores de direito internacional ocidentais se encontram na Associação de Direito Internacional para condenar essa mesma noção como sendo panfletária. As conferências Pacem in Maribus de 1970 a 1994 compóem um espaço paralelo aos trabalhos universitários-eruditos e às tomadas de decisão na ONU. Essas reuniôes contribuem para a formalização dessa ideia nascente e ainda amorfa de "patrimônio comum da humanidade" e, por meio desse trabalho, elas conferem um tipo de legitimidade às posições defendidas pelos países em desenvolvimento nas negociações da conferência. Essas reunióes, por fim, nos mostram como as clivagens políticas que se institucionalizam na ONU são transferidas para o espaço profissional jurídico estadunidense, dividindo os "juristas-guardióes-da-doutrina" dos "militantesidealistas-do-direito-internacional”. Face ao débil engajamento dos professores universitários num trabalho de explicação (e de consequente legitimação) doutrinária, os atores nesse outro espaço "simulam" racionalizações semelhantes, mesmo se as mesmas possam ser deficitárias do ponto de vista do "melhor" capital simbólico jurídico $(2)^{6}$. Ao longo dos anos, esse trabalho consagrará Borgese como uma especialista do Direito e da Política Internacional do Mar, e o IOI como uma instituição no seio da qual uma nova regra de Direito poderá ser interpretada e formalizada, longe do monopólio dos guardióes da doutrina jurídica internacional. Aqui, ao invés de nos aproximarmos das análises sobre os advocacy networks (KECK e SIKKINK, 1998) em Relações Internacionais ou sobre as comunidades epistêmicas (HAAS, 1992), nossa análise visa mais explorar as posições e oposições que conectam o macro com o micro a fim de desfazer a aparente homogeneidade entre as organizaçóes que trabalham, cada uma à sua maneira, para fortalecer uma ordem jurídica internacional.

\footnotetext{
6 Embora não seja analisado aqui, nossa extrapolação teórica não exclui que, se a maioria dos professores juristas-universitários escrevem publicamente artigos condenando o princípio, outros como Sohn, e por conta de seus engajamentos anteriores na contrução do sistema ONU, se encontram num jogo duplo (DEZALAY, BIGO, COHEN, 2015) entre construir o direito internacional e representar seu país.
} 


\section{d) A nacionalização da guerra politica internacional}

Assim, se faz necessário relembrar que a Associaçáo de Direito Internacional dos juristas professores - é monopolizada pelos profissionais do direito dos países ocidentais enquanto a Pacem in Maribus e o IOI - dos juristas ativistas - acolhem profissionais mais diversificados para falar de direito internacional, tais como os juristas e diplomatas dos países não-ocidentais. A clivagem política internacional entre países industrializados e em desenvolvimento, própria às negociações onusianas, é importada para esse espaço de expertise, primeiramente americano, e cada vez mais internacional, mas ainda assim ocidental. Em face de tal constatação, é cabível a hipótese de uma nacionalização das guerras políticas internacionais. Trata-se de uma nacionalização que se instala no seio [ao mesmo tempo que ela se alimenta] das concorrências profissionais sobre quem são os interpretes legítimos do direito internacional. Essa concorrência profissional toma sentido principalmente nos espaços nacionais mais centrais da ordem internacional ${ }^{7}$. Por meio dessa afirmação, nossa análise responde à incitação de Yves Dezalay (1993, p. 239) que chama a "considerar a produção doutrinária como um problema [também] social e profissional”. Por um lado, o engajamento dos atores diplomáticos na criação e produção dessas instituições a caráter de expertise torna imprecisa a fronteira entre a produção normativa - ou o processo de negociação onusiano de redação das leis da CNUDM - e a produção doutrinária - ou as interpretações do que se passa dentro da ONU, de acordo com a "ciência" do Direito.

Por outro lado, esse mesmo engajamento tem como efeito desordenar temporariamente os papéis de intérpretes do direito internacional designados tradicionalmente aos professores-eruditos do direito internacional, principalmente os docentes universitários com reputação mundial. O trabalho dos juristas dos thinktanks infringe a divisão hierarquizada do trabalho doutrinário ou da dominação simbólica dos professores de direito graças ao peso da aliança numérica do G77 na Assembleia Geral da ONU.

A participação dos diplomatas dos países em desenvolvimento acentua a clivagem entre juristas-universitários e ativistas pelo direito internacional na medida

\footnotetext{
7 Por exemple, a ativista Borgese e o advogado de direito empresarial e membro da Associação, Nothcutt Ely, defendem alternativas completamente opostas na audiência da comissão de assuntos exteriores do Senado estadunidense em julho de 1969, numa disputa clara sobre como o Estado norteamericano deve tratar o tema dos fundos marinhos. (US SENATE, 1969).
} 
em que esses últimos conseguem participar dos processos de produção normativa e doutrinária graças aos atores dominados da política interestatal. Aqueles que são historicamente dominados no espaço internacional se aliam aqui aos intérpretes menos legítimos do direito internacional para promover uma codificação inédita e contrária aos interesses governamentais ocidentais. Em outras palavras, o sul do Norte se alia ao norte do Sul. Nesse sentido, estudar as relaçôes de importação e exportação da produção doutrinária (entre o espaço nacional estadunidense e o espaço internacional da ONU) nos permite ver como essas redes de expertise-ativismo se enraízam nacionalmente (LEFRANC, 2008) e, principalmente, como as estratégias anti-hegemônicas internacionais se estruturam socialmente graças também às divisões nos espaços nacionais mais centrais.

No entanto se faz necessário destacar que, na medida em que o trabalho de produção doutrinária dos think-tanks depende da aliança política dos países em desenvolvimento no âmbito da Assembleia Geral da ONU, este trabalho é frágil no tempo longo. Uma vez as negociaçôes terminadas nos anos 1980, o Instituto de Borgese (IOI) continua suas atividades, mas não possui a mesma força social, visto que alguns dos seus mais altos membros diplomáticos morrem e outros se encontram ocupados com outras negociações, outras atividades diplomáticas mais urgentes. Porém, quando a conferência termina em 1982, o patrimônio comum da humanidade encontra-se inscrito oficialmente na Convenção das Naçôes Unidas sobre o Direito do Mar através de um conjunto de regras que materializam a interpretação promovida por esses atores e por Borgese durante toda a década de 1970. Se os juristas-universitários podem finalmente recuperar certa autonomia e exclusividade na atividade de interpretação doutrinária da convenção, eles têm, no entanto, que se confrontar com as novas regras oficializadas pela convenção e que agora são leis.

\section{Conclusão}

Esse artigo procurou transpor a análise de Dezalay e Garth (2002) sobre a mundialização da expertise de Estado à produção normativa internacional e multilateral que ocorreu entre 1973 e 1982 no espaço político da Assembleia Geral da ONU. Através do estudo dos profissionais do direito internacional que encontramos nesse espaço, constatamos que a autonomia dos guardióes tradicionais do direito internacional passa por um "desordenamento", uma suspensão da ordem 
tradicional de dominação, provocado por outros juristas intimamente conectados às alianças políticas que se forjam na ONU. Os grandes professores e advogados ocidentais (principalmente estadunidenses, citados em nosso estudo) se veem obrigados a se confrontarem com os juristas ativistas dos think-tanks ocidentais e os diplomatas dos países em desenvolvimento. Estes últimos encontram nesses espaços alternativos um novo lugar de expressão, além daquele da Assembleia Geral da ONU.

Nessa aliança temporária, estável enquanto a III Conferência das Naçóes Unidas sobre o Direito do Mar durar, os atores políticos diplomáticos investem na cisão entre os grandes professores de direito e os ativistas estadunidenses numa disputa pela autoridade de nomear o Direito Internacional. Enquanto os professores, mundialmente renomados, integram as delegaçôes ocidentais e influenciam o jogo a partir do centro, os negociadores diplomáticos dos países dominados se servem da guerra de palácios americana para influenciar também pelas margens da negociação, na medida em que eles trabalham em estreita colaboração com os juristas dos thinktanks. Eles rivalizam assim com a centralidade dos grandes professores e advogados ocidentais e sustentam um centro imperfeito, concorrente e passageiro, de exportação de regras e interpretaçóes de regras do direito. Uma estratégia anti-hegemônica se instala a partir das dinâmicas políticas situadas no espaço internacional e transnacional onusiano. Tal estratégia nos leva a responder nossa questão inicial com um "sim, mas não completamente". Na medida em que constatamos certa unificação do saber jurídico internacional nas delegaçôes, constatamos também a abertura de espaços de luta anti-hegemônicas que são, não obstante, relativamente dependentes do centro do sistema mundial.

- Natália Frozel Barros é Doutoranda em Ciência Política na Université de Paris I Panthéon-Sorbonne (Laboratório CESSP-UMR 8209). E-mail: nfrozelb@hotmail.com.

\section{Referências}

ALMEIDA, Ana Maria F. (Orgs.). Circulação internacional e formação intelectual das elites brasileiras. Campinas: Editora UNICAMP, 2004. 
BAKER, Betsy B. Uncommon Heritage: Elisabeth Mann Borgese, Pacem in Maribus, the International Ocean Institute and Preparations for UNCLOS III. Ocean Yearbook, v. 26, p. 11-34, 2009.

BOURDIEU, Pierre. La noblesse d'État: grandes écoles et esprit de corps. Paris: Les Éd. de Minuit, 1989.

DE SOTO, Alvaro. Reflections on UNCLOS III: Critical Junctures. Law and Contemporary Problems, v. 46, n. 2, p. 65-69, 1983.

DEZALAY, Yves. Marchands de droit: la restructuration de l'ordre juridique international par les multinationales du droit. Paris: Fayard, 1992.

La production doctrinale comme objet et terrain de luttes politiques et professionnelles. In: POIRMEUR, Yves; BERNARD, Alain (Orgs.). La doctrine juridique. Amiens: Curapp, 1993, p. 230-239.

DEZALAY, Yves; GARTH, Bryant G. La mondialisation des guerres de palais: la restructuration du pouvoir d'Etat en Amérique latine, entre notables du droit et Chicago boys. Paris: Seuil, 2002.

DEZALAY, Yves; BIGO, Didier; COHEN, Antonin. Enquêter sur l'internationalisation des noblesses d'État. Retour réflexif sur des stratégies de double jeu. Cultures \& Conflits, v. 98, n. 2, p. 15-52, dez. 2015.

ENGELMANN, Fabiano. Globalização e poder de Estado: circulação internacional de elites e hierarquias do campo jurídico brasileiro. Dados: revista de ciências sociais, Rio de Janeiro, v. 55, n. 2, p. 487-516, 2012.

FINNEMORE, Martha; SIKKINK, Kathryn. International Norm Dynamics and Political Change. International Organization, v. 52, n. 4, p. 887-917, 1998.

FRANCK, Thomas M. Tribute to Professor Louis B. Sohn. Harv. Int'l L.J., v. 48, n. 1, p. 23-24, 2007.

HAAS, Peter M. Introduction: epistemic communities and international policy coordination. International Organization, v. 46, n. 1, p. 1-35, jan. 1992.

INTERNATIONAL LAW ASSOCIATION (ILA). Law of the Sea. 57 Int'l L. Ass'n Rep. Conf., 321, 451, 1976.

. 58 Int'l L. Ass'n Rep. Conf., 1978.

KECK, Margaret E.; SIKKINK, Kathryn. Activists beyond borders: advocacy networks in international politics. Ithaca: Cornell University Press, 1998.

KOSKENNIEMI, Martti. The gentle civilizer of nations: the rise and fall of modern international law 1870-1960. Cambridge: Cambridge University Press, 2002.

LEFRANC, Sandrine. Du droit à la paix: La circulation des techniques internationales de pacification par le bas. Actes de la recherche en sciences sociales, v. 174, n. 4, p. 48-67, 2008.

MAZOWER, Mark. Governing the world: the history of an idea. Londres: Penguin Books, 2013.

PERISSINOTTO, Renato M.; CODATO, Adriano. Apresentação: por um retorno à Sociologia das Elites. Revista de Sociologia e Política, v. 16, n. 30, p. 7-15, jun. 2008.

RATINER, Leigh S. The Law of the Sea: A Crossroads for American Foreign Policy. Foreign Affairs, v. 60, p. 1006-1021, 1982. 
RICHARDSON, Elliott. Dispute Settlement under the Convention on the law of the sea: a flexible and comprehensive extension of the rule of the law to ocean space. In: BUERGENTHAL, Thomas (Orgs.). Contemporary issues in international law: essays in honor of Louis B. Sohn. Kehl, 1984.

SACRISTE, Guillaume; VAUCHEZ, Antoine. Les «bons offices» du droit international: la constitution d'une autorité non politique dans le concert diplomatique des années 1920. Critique internationale, v. 26, n. 1, p. 101-117, 2005.

TELTSCHNYT, Kathleen. Harvard Professor the 'Guru' of Sea Law Talks. New York Times, 16 de julho de 1977, p. 4.

UNITED STATES SENATE. Activities of Nations in Ocean Space: hearings before the United States Senate Committee on Foreign Relations, Subcommittee on Ocean Space. Ninety-First Congress, first session, Washington, 24, 25, 28, 30 julho de 1969.

VISWANATHAN, Vivek. Crafting the law of the sea. Elliot Richardson and the Search for Order on the Oceans (1977-1980). Harvard College, 2009.

Texto recebido em 19 de abril de 2018. Aprovado em 23 de outubro de 2018. 